\title{
PROFESSIONAL NURSES' REQUESTS TO REMOVE THEIR NAMES FROM THE SOUTH AFRICAN NURSING COUNCIL'S REGISTER \\ PART 2: RESEARCH PROCESS AND RESULTS
}

\section{Dr Valerie J Ehlers}

B Soc Sc (Nursing); Honours BA (SS) (Psychology; BA Cur; Honours BA Cur; MA Cur; D Litt et Phil; Diploma in Development Studies

Senior Lecturer, Department of Health Studies, Unisa

Correspondence: ehlervj@unisa.ac.za

Keywords: baby boomers; migration of nurses; non-practising nurses; nurses' turnover; nursing shortages; professional re-entry of nurses; retirement of nurses

\section{SUMMARY}

In this article data obtained from questionnaires, completed by 91 professional nurses who requested their names to be removed from the South African Nursing Council's register for the 2000 registration year, are presented and discussed. The ages, marital status, professional and academic qualifications of these 91 respondents provided background information for interpreting their major reasons for leaving and/or re-entering the nursing profession. Recommendations are provided to address the anticipated depletion of registered nurses, and to increase the number who re-enter the nursing profession in South Africa.

\section{OPSOMMING}

In hierdie artikel word data wat vanaf 91 vraelyste verkry is en deur professionele verpleegkundiges voltooi is wat versoek het dat hulle name van die Suid-Afrikaanse Raad op Verpleging se register verwyder word vir die 2000 registrasiejaar, bespreek. Die ouderdomme, huwelikstatus, professionele en akademiese kwalifkasies van die 91 respondente verskaf agtergrondinligting, waarteen die hoofredes vir hulle uittrede uit en/of hertoetrede tot die verpleegprofessie, vertolk word. Aanbevelings word gedoen om die verwagte uitgedunde geledere van professionele verpleegkundiges aan te spreek, asook wyses waarop die getal wat hertoetree tot die verpleegprofessie in Suid-Afrika verhoog kan word. 


\section{INTRODUCTION}

The previous article indicated that a global shortage of professional nurses can be expected between 2005 and 2020. Countries which pay better salaries and offer good employment conditions will continue to attract professional nurses from poorer paying countries, including the Republic of South Africa (RSA). This emphasises the dire need for the RSA to monitor all nurses abandoning the nursing profession or emigrating from the RSA. The purpose of this research is to address the anticipated depletion of professional nurses in the RSA and to contribute to the avoidance of a potential crisis regarding the shortage of professional nurses in the RSA. The major objectives which guided this research, were to identify reasons why professional nurses requested their names to be removed from the SANC's register, and to identify factors which could prohibit or facilitate their professional re-entry. In order to contextualise these findings information was also requested about personal data such as age, marital status, professional and academic qualifications.

This article will describe the research methodology adopted to investigate reasons why professional nurses requested their names to be removed from the SANC's register. The research results will be presented and discussed, followed by recommendations for addressing the anticipated shortage of professional nurses in the RSA.

\section{RESEARCH METHODOLOGY}

A non-experimental, exploratory, descriptive and quantitative survey (Burns \& Grove, 2001:52) was adopted using questionnaires to obtain data about professional nurses who requested their names to be removed from the SANC register in 2000.

\section{Research population}

The target population comprised all professional nurses who requested their names to be removed from the SANC register in 2000. At the researcher's request, the SANC supplied name and address stickers of a computerised randomly drawn $20 \%$ sample of all persons who made such requests for the 2000 registration year. The target population comprised all persons who requested the removal of their names from the SANC's registers in 2000 and the sample comprised those 190 persons $(\mathrm{N}=190)$ constituting the $20 \%$ sample selected by the SANC computer programmer. As the 190 questionnaires were sent out anonymously, no follow-up procedures could be done to improve the return of completed questionnaires. $A$ total of $91(n=91 ; 48.9 \%)$ usable completed questionnaires were received and provided the data presented and discussed in this report. Questionnaires were discarded which contained only biographic information as well as two questionnaires completed by enrolled nurses and one which indicated that she was "scrapped" from the SANC register and thus did not request that her name be removed from the SANC register.

\section{Research instrument}

A questionnaire, comprising open and closed ended questions, was compiled utilising information obtained from the literature review, in an attempt to obtain reliable data pertaining to nurses' reasons for requesting their names to be removed from the SANC register, and for identifying factors which could facilitate or impede their professional re-entry. "The reliability of an instrument is the degree of consistency with which it measures the attribute it is supposed to be measuring" (Polit \& Hungler, 1991:242). Two experienced nurse researchers were requested to review the questions critically as well as two retired nursing colleagues who maintained their SANC registration, and who did not form part of the research population, in order to evaluate the relevance of each questionnaire item to the research problem as well as the comprehensibility of each item. These four persons indicated that the questions were easily understood, that the questions were unambiguous, except in two cases where they doubted the precise meaning of the questions. Two minor changes in terminology were effected according to their comments. These changes included clarifying academic qualifications to be degrees and non-nursing diplomas; and rephrasing the question about encouraging their daughters to become nurses to read: "Suppose you have an eighteen year old daughter, would you encourage her to become a registered nurse?" Validity refers to the degree to which an instrument measures what it is supposed to measure (Polit \& Hungler, 1991:246). Content validity, the 
adequacy of the content being covered by the questions, was assessed by four nursing colleagues, who judged the content to be relevant to the research problem. Content validity was further explored by comparing the results of questions pertaining to similar issues, such the respondents' ages and the number of years they were registered with the SANC and the major reason for requesting their names to be removed from the SANC register being retirement.

The questionnaire consisted of two major sections, attempting to obtain data about the respondents':

- biographic profile, including age, marital status, professional and academic qualifications, and current studies; and

- $\quad$ professional profile including reasons for leaving the nursing profession, possible other jobs, willingness to encourage others to pursue a nursing career, and conditions under which they would consider re-entering the nursing profession.

\section{Ethical considerations}

The target population for this survey comprised professional nurses who requested their names to be removed from the SANC register in 2000 . Consequently they could reflect their real experiences and/or perceptions without fear of intimidation from nursing colleagues or from employers. The questionnaires were completely anonymous and contained no numbers for identifying respondents/nonrespondents at a later stage. In order to maintain the anonymity and confidentiality, no written permission was requested to participate in the research. The fact that a person completed a questionnaire freely and in his/ her own time, indicated the person's willingness to participate in the research. This procedure assured the confidentiality and anonymity of all responses received. The respondents who returned completed questionnaires, did so voluntarily, without any coercion, without any follow-up reminders, and without any remuneration. Thus the respondents complied with the elements of informed consent, namely

- disclosure of essential information

- comprehension

- competency

- $\quad$ voluntarism (Burns \& Grove, 2001:206).

A stamped self-addressed envelope was enclosed with each questionnaire, enabling each respondent to seal the completed questionnaire in an envelope and post it him/herself without making contact with any person. A cover letter was enclosed with each questionnaire, explaining the purpose of the research and re-assuring each participant that no persons nor institutions will be mentioned in the research report, that the data obtained from the questionnaires will be analysed and interpreted and published as a research report (Burns \& Grove, $2001: 430)$. This cover letter also explained that the contact details were obtained by the SANC's data base that identified persons who requested their names to be removed from the SANC register. Those persons who wished to obtain such a research report could send a separate letter to this intent to the researcher or they could phone to request such a report - the researcher's telephone number was included in the cover letter. Approximately ten phone calls were received, mainly to discuss the professional problems respondents encountered, but no one requested a report to be sent to him/her personally once they were assured that it would be submitted for publication within the RSA.

\section{The data gathering process}

The questionnaires were posted together with a cover letter explaining the purpose of the research and requesting the return of the completed questionnaires within four weeks. Respondents could complete the questionnaire within 30 minutes. A few telephone enquiries requested extension of time to submit the completed questionnaires, or to inform the researcher that the addressee was too ill and/or frail to complete any questionnaire (three potential respondents).

After a period of 12 weeks had elapsed since posting the questionnaires, the 91 usable completed questionnaires were used for data analysis. Another ten returned questionnaires contained only one or two answers and were thus discarded as non-usable. No follow-up questionnaires were posted as the nonrespondents could not be identified and as the costs of sending follow-up questionnaires to all possible respondents would have been prohibitive.

\section{Data analysis}

As this research was conducted as an exploratory, quantitative survey and as no hypotheses were 
formulated, the responses from the 91 questionnaires were transferred to the Epilnfo computer program. Frequencies and percentages were calculated and displayed in tables, and pie or bar diagrams. In this way the raw data from the questionnaires were summarised, organised and systematised for this report (Polit \& Hungler, 1991:260).

Cross referencing between the answers obtained to different questions was also done. For example, the respondents' ages correlated with the number of years they were reportedly registered with the SANC prior to requesting the removal of their names from the SANC register.

\section{RESEARCH RESULTS}

\section{Biographic information}

In order to contextualise the data pertaining to reasons for leaving the nursing profession, and possible impeding professional re-entry, some personal information about the respondents was required, including their ages, marital status, professional and academic qualifications, the pursuit of further studies as well as employment in fields other than nursing.
Each of these aspects will be briefly discussed under separate subheadings.

\section{Age}

The figures and percentages in Table 1 reflect that only a minority of respondents ( 8 or $8.8 \%$ ) were 39 years old or younger when they requested the removal of their names from the SANC's register. This implies that recruitment efforts directed at non-practising nurses younger than 40 years of age might meet with limited success as less than $10 \%$ of the nurses who requested their names to be removed from the SANC register in 2000 were younger than 40 years of age. However, it is possible that a number of nurses in this age group no longer practise as professional nurses but maintain their SANC registration (excluding them from participation in this study), in case they might need to re-enter the nursing profession at a future stage of their lives. This possibility will only be accessible to investigation if the SANC's annual registration documents and computerised data would request professional nurses to indicate whether they were employed (full time, part time, not at all) as professional nurses at the time of renewing their annual SANC subscriptions.

\section{Table 1: Age of respondents}

\begin{tabular}{|l|l|l|l|l|}
\hline Age & Number (n) & $\begin{array}{l}\text { Percentage } \\
(\%)\end{array}$ & $\begin{array}{l}\text { Cumulative } \\
\text { frequency (cf) }\end{array}$ & $\begin{array}{l}\text { Cumulative } \\
\text { percentage (\%) }\end{array}$ \\
\hline $\begin{array}{l}29 \text { or } \\
\text { younger }\end{array}$ & 2 & 2.2 & 2 & 2.2 \\
\hline $30-39$ & 6 & 6.6 & 8 & 8.8 \\
\hline $40-49$ & 15 & 16.5 & 23 & 25.3 \\
\hline $50-54$ & 9 & 9.9 & 32 & 35.2 \\
\hline $55-59$ & 17 & 18.7 & 49 & 53.9 \\
\hline $60-64$ & 17 & 18.7 & 66 & 72.6 \\
\hline $65-69$ & 18 & 19.7 & 84 & 92.4 \\
\hline 70 or older & 7 & 7.7 & 91 & 100.0 \\
\hline
\end{tabular}




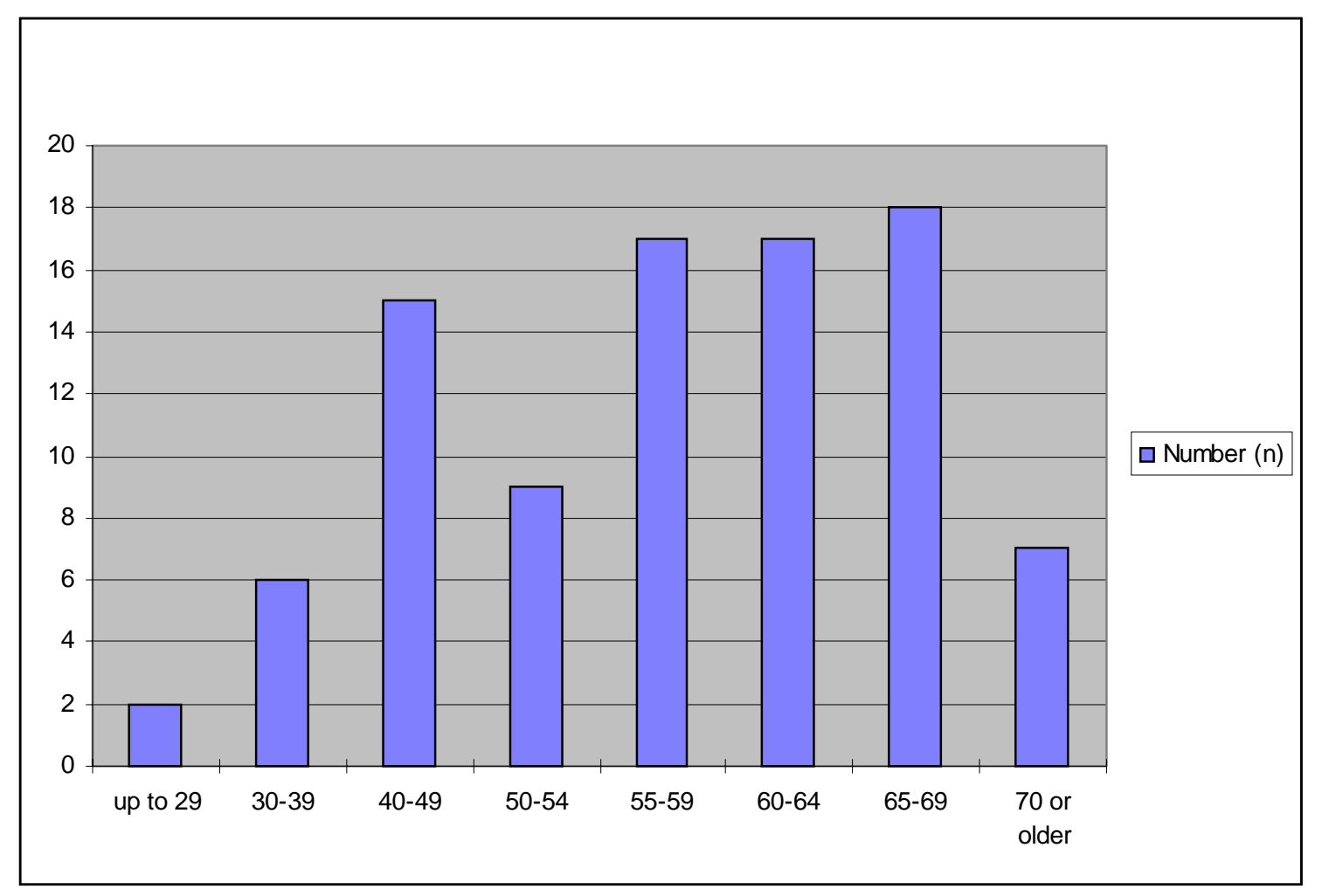

Figure 1: Ages of respondents

The age distribution of the 91 respondents appears to be bimodal with high frequencies in the age groups of 40-49 and 55-69 (comprising the three age groups of 55-59; 60-64 and 65-69). This might indicate that more or less similar numbers of professional nurses in the RSA retire from the ages of 55 to 65 . Nineteen years ago Cilliers (1984:74) warned that the then median age of 38 years of the RNs in the RSA, should alert health care planners. These findings seems to correlate with the warning heeded by Cilliers, forecasting that the majority of these RNs would retire between 2005 and 2010, if they chose to retire between the ages of 60 and 65 . The warnings from authors from the UK and the USA about the approaching retirement of the "baby boomers" also seem to be relevant (Minnick, 2000:217; Purnell, Horner, Gonzales \& Westman, 2001:179; Sochalski, 2001; Tanner \& Bellack, 2001:100).
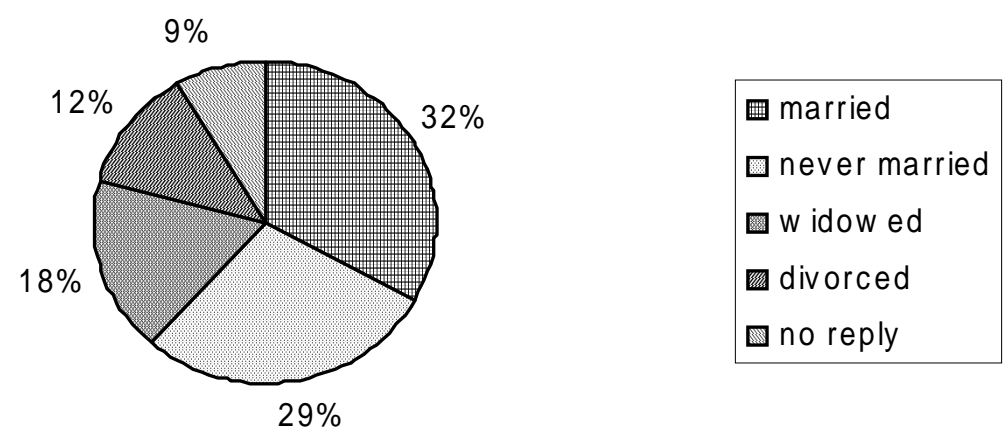

Figure 2: Marital status of respondents 


\section{Marital status}

The respondents indicated their marital status as follows:

- married: 30 (33.0\%)

- never married: 26 (28.6\%)

- widowed: $16(17.6 \%)$

- divorced: $11(12.1 \%)$

- no answer: 8 (8.7\%).

Those $30(33.0 \%)$ respondents who were reportedly married, could be expected to consider retirement when their husbands retired, and might thus not be able to consider postponing their retirements.

However, as 53 (or $58.30 \%$ ) were not married (never married, divorced or widowed) at the time they requested their names to be removed from the SANC register, they might agree to work additional years should the pension and/or tax benefits be sufficiently attractive to make such ventures financially worthwhile.

Table 2: Professional (nursing) qualifications

\begin{tabular}{|l|l|l|l|}
\hline General Nursing & 91 & Intensive (Critical) Care & 4 \\
\hline Midwifery & 61 & Paediatric Nursing & 3 \\
\hline Community Health Nursing & 12 & PHC (Primary Health Care) & 2 \\
\hline Psychiatric Nursing & 8 & Occupational Health & 2 \\
\hline Gerontology & 6 & Opthalmological Nursing & 2 \\
\hline Operating Theater & 6 & Oncological Nursing & 1 \\
\hline Nursing Administration & 5 & Ward Administration + Clinical Teaching & 1 \\
\hline Nursing Education & 5 & Tropical Diseases & 1 \\
\hline Trauma Nursing & 1 & Chronic Diseases (TB) & 1 \\
\hline
\end{tabular}

\section{Professional (nursing) qualifications}

All respondents $(91 ; 100 \%)$ were qualified general nurses with a large number $(61 ; 67.0 \%)$ also being qualified midwives. However, the respondents possessed a wide variety of nursing qualifications which could have been useful to many diverse South African health care situations, as reflected in Table 2.

\section{Academic qualifications}

Only a limited number of respondents possessed academic qualifications, namely six $(6.6 \%)$ had BA degrees and two $(2.2 \%)$ had MA degrees. One respondent indicated that she acquired certificates in "open water scuba diving".

\section{Pursuit of further studies}

Only one respondent indicated that she was pursuing Biblical Studies and another one was doing a BA degree, majoring in Industrial Psychology. No major career changes were contemplated by these respondents.

\section{Reasons for further studies}

"For a closer walk with God" and "to make my working environment more pleasant" were the reasons provided by the two respondents who pursued further studies. Both intended using their newly acquired knowledge in fields outside the nursing profession.

\section{Number of years registered with the South African Nursing Council (SANC)}

The cumulative percentage column in Table 3 reflects that only $26(28.6 \%)$ of the 91 respondents were registered with the SANC for less than 20 years prior to requesting the removal of their names from the SANC register. This age group would be one of the most worthwhile groups to target for potential professional re-entry, but due to its small size, this might not make any impact on the nursing shortage in the RSA. Thus the warnings from USA and UK researchers that future nurse shortages will not be replenishable from the ranks of non-practising nurses whose numbers will be too 
Table 3: Number of years registered with the South African Nursing Council (SANC)

\begin{tabular}{|l|l|l|l|l|}
\hline $\begin{array}{l}\text { Number of years } \\
\text { registered with }\end{array}$ & Number (n) & Percentage (\%) & $\begin{array}{l}\text { Cumulative } \\
\text { frequency (cf) }\end{array}$ & Cumulative \\
percentage (\%)
\end{tabular}

small, appear to be applicable to the RSA as well (Minnick, 2000:211; Buerhaus, 1998:107). These authors also indicated that nurse shortages during the 1980s were managed by recruiting large numbers of non-practicing professional nurses but that these numbers will continue to decline as more and more "baby-boomers" reach their retirement ages between 2005 and 2020.

The bimodal distribution reflected in Figure 3 (number of years registered with the SANC), reflects peaks similar to those of Figure 1 (ages of respondents).

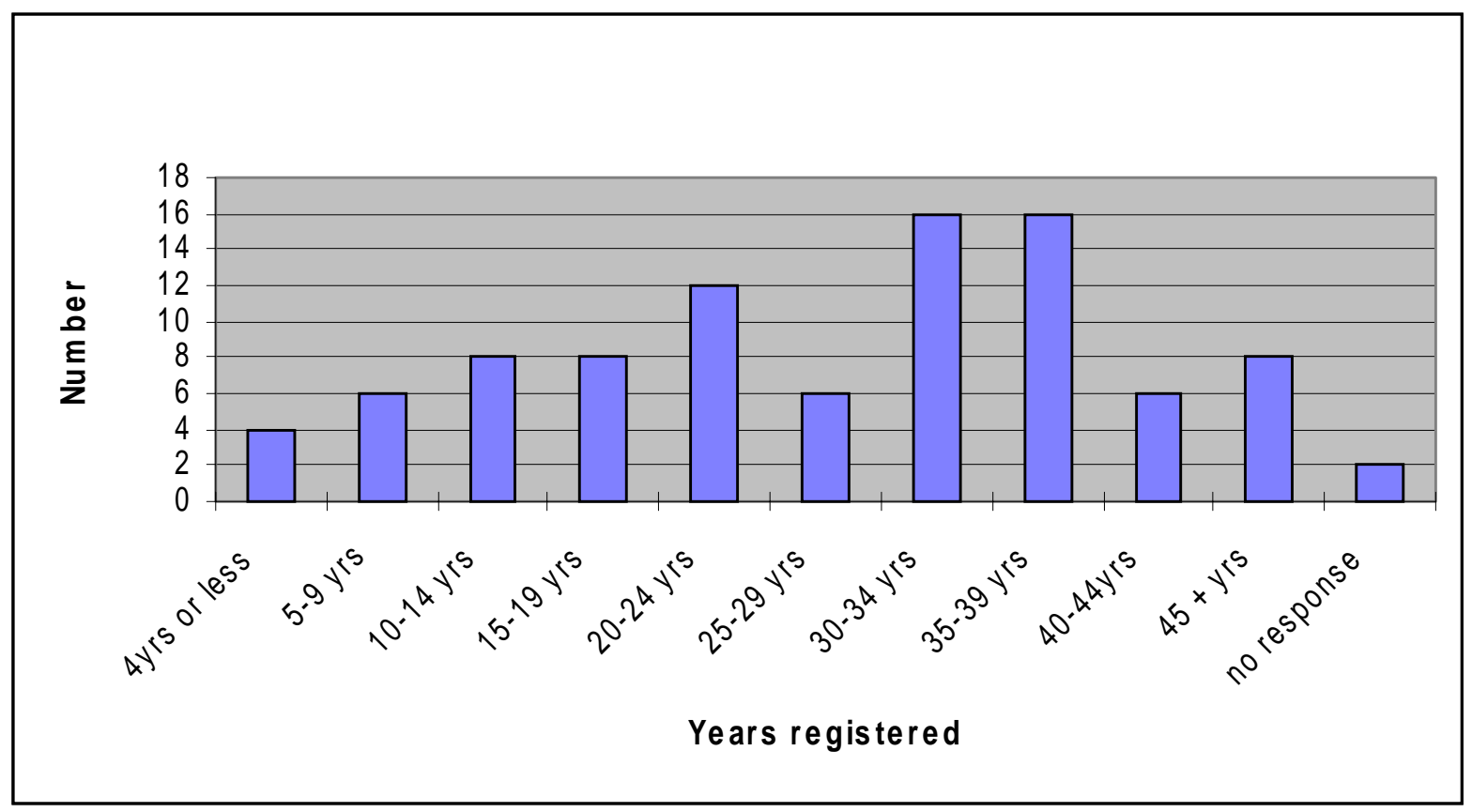

Figure 3: Number of years registered with the SANC 
Those 12 respondents who maintained their SANC registration for 20-24 years would probably fall within the age group of 40-49 if they became RNs in their twenties. Whereas those who maintained their SANC registrations for 30-39 years would probably be aged between 55 and 69 when they requested the removal of their names from the SANC register. Therefore the findings to these two questions seem to correlate as expected.

\section{Number of years of working as professional nurses prior to requesting that their names be removed from the SANC register}

Very few respondents answered this question, but the three who indicated the longest periods of working as registered nurses prior to canceling their registration with the SANC, indicated this period to be 40,35 and 27 years respectively. A wealth of professional experience must have been accumulated over this period of time. The health care system of the RSA could definitely benefit by creating part time positions for such experienced persons to continue to render meaningful inputs into enhancing the quality of the RSA's citizens' lives. According to Peterson (2001:5) “... very little research has been done, particularly within nursing, about the impact of the aging workforce and potential accommodations that may need to be made in order to retain the experienced nurse". In Belgium a strategy was implemented to retain experienced nurses within the active professional ranks by enabling nurses older than 45 to work for 36 hours per week; and those older than 55 to work for 32 hours per week, whilst being paid for a standard 38 hour working week (Williams in Peterson, 2001:5).

\section{Reasons for requesting the removal of names from the SANC register}

Only a limited number of responses were provided to this open-ended question. The reasons provided for requesting the removal of their names from the SANC register varied but included:

- reaching retirement age (33 or $36.3 \%$ with ages ranging from 50 to 67$)$

- emigration (5 or $5.5 \%$ of whom 1 emigrated to the UK and 1 to Germany)

- that the annual SANC registration fee could no longer be afforded (3 or 3.3\%)

- that they never want to nurse again (3 or $3.3 \%$ aged 52-57)

- they retired because their husbands retired (2 or $2.2 \%$ aged 50 and 52 )

- dissatisfaction with the low salaries of nurses (2 or $2.2 \%$ aged 42 and 44 )

- being retrenched (1 or $1.1 \%$ - no age provided)

- that the nearby hospital closed down and no other nursing job could be found (1 or $1.1 \%$ who indicated no age)

- taking early retirement (1 or $1.1 \%$ aged 59 ) to take care of her 91 -year old mother

- becoming a music teacher (1 or $1.1 \%$ who has a Master's degree in nursing)

- being dissatisfied with the low standard of nursing care (1 or $1.1 \%$ aged 43 years)

- experiencing health problems $(16 ; 17.6 \%)$ which included

- back problems (8 or $8.8 \%$ with ages ranging from 34 to 52 )

- osteoporosis (4 or $4.4 \%$ with ages ranging from 49 to 55$)$

- (unspecified) injury on duty (1 or $1.1 \%$ )

- multiple sclerosis (1 or $1.1 \%$ aged 44 )

- impaired vision ( 1 or $1.1 \%$ aged 59 )

- cancer (3 or 3.3\% aged 50-59)

- foot operations ( 1 or $1.1 \%$ aged 55 )

- tuberculosis and asthma (1 or $1.1 \%$ aged 70 ).

Although it became evident that the majority of the respondents requested removal of their names from the SANC register because of retirement, further data analysis of the questionnaires from the 40-49 year age group was attempted, because these respondents could theoretically have spent another 15 to 25 years within the professionally active nursing ranks. It could be ascertained from the responses provided to openended questions that out of $15(16.5 \%)$ respondents aged 40-49, who requested the removal of their names from the SANC register, did so because of

- poor health (4 or 4.4\%: arthritis/osteoporosis, multiple sclerosis, unspecified injury on duty, back problems)

- emigration (2 or $2.2 \%$ : one to the United Kingdom and one to Germany)

- the SANC registration fees which became unaffordable (3 or 3.3\%) 
- $\quad$ no need to work (3 or 3.3\%)

- disillusionment with the nursing profession (2 or $2.2 \%$ who maintained that they were not recognised as professional persons while they were nursing, but received such recognition in their current jobs in the manufacturing and sales businesses respectively).

Thus none of the respondents aged 40-49 would seem to contemplate re-entering the nursing profession.

Those respondents aged 50-54 might have been able to render another 5-15 years' service (assuming that they would retire between the ages of 60 and 65) if they could be assisted to re-enter the nursing profession. Out of the nine respondents aged 50-54, four (4.4\%) left the nursing profession because of health reasons, two (2.2\%) because their husbands retired, two $(2.2 \%)$ because they did not work for some time, and one $(1.1 \%)$ because she found a job as a receptionist. According to these responses it seems to be unlikely that any of these respondents could be recruited for re-entering the nursing profession.

\section{Employment status}

The respondents were requested to indicate whether they were working full time, part time or not at all. Only $61(67.0 \%)$ respondents replied to this question, of whom

- 47 (51.6\%) were not working at all - as expected according to the age distribution reflected in Table 1

- $10(10.9 \%)$ were working full time

- 4 (4.4\%) were working part time.

\section{Hours worked}

Every respondent who worked part or full time, seemed to work different hours. Interestingly, three indicated that they were working 12-hour shifts three days per week; one started work at 07:15 and another at 07:30. Only one respondent indicated that she worked hours which suited her because her schedule was sufficiently flexible to accommodate her preferences. Thus the number of hours worked did not seem to be a major influence to select another job, but at least five respondents indicated that the regular hours, rather than the rotating shifts of nursing duties, were more acceptable to them and/or their families.

\section{Major duties}

An open-ended question requested respondents to indicate what the major duties of their current jobs encompassed. These responses were divided into two major groups, namely those comprising major duties relevant to nursing and those falling outside the scope of nursing. The major duties in each category included:

- non-nursing duties

- $\quad$ direct sales (2 or $2.2 \%$ )

- $\quad$ typing and bookkeeping (2 or $2.2 \%$ )

- managing a retail store or a manufacturing business ( 2 or $2.2 \%$ )

- $\quad$ teaching music (1 or $1.1 \%$ )

- $\quad$ being a receptionist (1 or $1.1 \%$ )

- being a flower farmer (1 or $1.1 \%$ )

- nursing related duties

- $\quad$ taking care of a mentally retarded child (1 or $1.1 \%$ )

- controlling theater and ward stock at a private clinic (1 or $1.1 \%$ )

- $\quad$ being an adult care giver (1 or $1.1 \%$ )

- working for the Cancer Association or for an AIDS organisation (2 or $2.2 \%$ ).

Although the 14 (15.4\%) non-practising nurses who were employed, performed a variety of jobs, at least five $(5.5 \%)$ provided some type of care as part of their duties.

\section{Reasons for preferring current jobs to that of being a professional nurse}

Ironically one (1.1\%) of these respondents indicated that she was working as a bookkeeping clerk, managing hospital fees, and that "... I could never earn in nursing what I earn now'. One (1.1\%) respondent indicated that she worked long hard hours for a drug company, at the age of 69 , but that she preferred this job to nursing, because "... I am treated like a responsible adult'. Other responses included the ability to work from home, not to work night duty nor on public holidays, and enjoying better job satisfaction than was possible in nursing.

Although only two (2.2\%) respondents indicated that they requested their names to be removed from the SANC's registers because they were dissatisfied with 
their salaries, five (5.5\%) indicated that they preferred their current jobs because their salaries were better than those of professional nurses.

Two $(2.2 \%)$ respondents seemed to concur that the inability to render the quality of nursing care they desired to give, made them leave the nursing profession. One stated: "I can serve from the heart without restriction of hospital care without the means to supply such care". The other one wrote: "I do not prefer this job. Nursing is just not the same anymore. The nurses do not give that special care to the sick anymore".

\section{Encouragement of their daughters to become registered nurses}

Respondents were requested to reply to a yes/no question as to whether or not they would encourage their 18-year old daughters to become registered nurses, (supposing they had 18-year old daughters). Only 77 respondents replied, with 44 (57.1\%) indicating "yes" and 33 (42.9\%) "no" to this question. Only one (1.1\%) respondent said he/she would encourage his/ her 18-year old daughter to become a registered nurse, provided that it would be the daughter's own decision “.. but I will not influence her". No further positive reasons were supplied for possibly encouraging their 18-year old daughters to become professional nurses. However a number of reasons for NOT encouraging their 18-year old daughters to become professional nurses were provided, including:

- $\quad$ poor salary (4 or $4.4 \%$ )

- long working hours (1 or $1.1 \%$ )

- dissatisfaction with the nursing profession as such (14 or $15.4 \%$ ), expressed as:

- too much pressure or stress at work (2 or $2.2 \%$ )

- nursing has no future (1 or $1.1 \%$ )

- since nursing became a trade union, it is no longer a profession (1 or $1.1 \%$ )

- nursing is no longer an emotionally worthwhile profession (1 or $1.1 \%$ )

- nursing is no longer recognised as a profession in South Africa (1 or 1.1\%)

- nursing conditions are unsatisfactory and/or unsafe (3 or 3.3\%)

- nursing offers no job satisfaction (3 or 3.3\%)

- nursing care deteriorated since my training days (1 or $1.1 \%)$
- nurses no longer work for the job, only for the money (1 or 1.1).

Nurses' dissatisfaction can be interpreted explicitly as nurses not encouraging others to choose nursing as a profession. Mills and Blaesing (2000:341) maintain that "This has serious recruitment and retention consequences as a nurse shortage begins". Nurse leaders and nurse planners should pay attention to the professional perceptions portrayed by these 14 (15.4\%) respondents. Improving these aspects are in the hands of the nurses themselves. Mcneese-Smith (2000:147) maintains "Organization commitment of the nurse bears a strong relation to mastery and preventing disengagement... In times of change and great financial pressure, these measures are critical to assist nurses to retain their ideals of service and to support their desire to improve the lives and health of patients". The importance of caring for nurses who care for patients cannot be overemphasised (Taylor \& Covaleski, 1985:237) - something which these respondents apparently did not encounter in their nursing careers. Soothill, Henry and Kendrick (1992:219) reported that the major reasons for leaving the nursing profession in the UK centered around working conditions, especially work loads which prevented nurses from providing safe and effective patient care, staff shortages and underfunded resources. "The heavy workload, staff shortages and lack of resources were getting between the nurse and the patient and also between nurses themselves" (Soothill et al. 1992:221). Similar experiences were reflected in these respondents' replies to the open-ended question as to why they would not encourage their 18-year old daughters to pursue nursing careers.

Although dissatisfaction with the low salaries of nurses caused two (2.2\% aged 42 and 44 ), to request the removal of their names from the SANC register, four $(4.4 \%)$ would not encourage their daughters to pursue nursing careers because of poor salaries. Thus although dissatisfaction with salaries apparently assumed greater importance in not encouraging others to enter the profession, than in causing them to request the removal of their names from the SANC register.

\section{Specific circumstances under which respondents would re-enter the nursing profession}


The responses supplied to this open-ended question, indicated that financial need would be the major motivating factor to consider re-entering the nursing profession. However, a variety of other conditions were also provided, including the possibility to work regular hours and to earn better salaries. The full range of responses included:

- if I really needed the income (10 or $11.0 \%)$ )

- if I could work regular hours (4 or $4.4 \%$ )

- if the salaries were better (3 or $3.3 \%$ )

- if nursing conditions would improve (3 or $3.3 \%$ )

- hopefully never (3 or 3.3\%)

- if a disaster situation should occur, and I could serve my country ( 2 or $2.2 \%$ )

- if my health (back problems) recovered sufficiently (2 or $2.2 \%$ )

- if DENOSA would become a professional organisation which does NOT encourage nurses to strike over uniforms ( 1 or $1.1 \%$ )

- if the hospitals jack up the chiefs to get off their buts and also do a day's work instead of drinking coffee all day long (1 or $1.1 \%$ )

- if discipline, responsibility and motivation were reintroduced into the nursing profession (1 or $1.1 \%$ )

- if I could find a job which accommodates my (unspecified) disability (1 or $1.1 \%$ aged 48 )

- if I could do a post basic course in psychiatric or trauma nursing (1 or $1.1 \%$ aged 47 )

- if the SANC fees would be lower, I would register and help in an old age home (1 or $1.1 \%$ ).

\section{Intention to do a re-entry course prior to re-entering the nursing profession}

Out of the $66(72.5 \%)$ respondents who answered this question, 25 (37.9\%) would do a re-entry course prior to re-entering the nursing profession, whilst 41 (62.1\%) would not do so. Only one respondent indicated that she might consider doing a re-entry course depending on her future place of employment. The importance of offering re-entry courses to non-practising nurses should not be underestimated by institutions hoping to appoint non-practising nurses to relieve shortages of professional nurses. Research conducted in the Gauteng Province of the RSA concluded that "An effective nurse re-entry course, some support for the newly appointed nurse and the assurance that she would not be left 'in charge' of a unit for the first six months subsequent to re-entry, would facilitate not only the recruitment of non-practising nurses, but also their long-term retention within the professionally active ranks" (Ehlers, 1994:27).

\section{LIMITATIONS OF THE RESEARCH}

The most important limitation of the survey is that only data obtained from completed questionnaires could be analysed and interpreted. There can be no guarantee that those professional nurses who completed questionnaires held the same beliefs and perceptions as those who failed to do so. There is also no warranty that those who requested the removal of their names from the SANC register, held perceptions and expectations similar to those who remained within the professionally active nursing ranks.

\section{RECOMMENDATIONS BASED ON THE RESEARCH RESULTS}

Notwithstanding the above limitations, some recommendations for future research and for addressing the nursing shortage in South Africa could be made, based on the research results.

\section{Recommendations for future research}

This study focused on professional nurses leaving the profession. Similar research should be done on those entering the profession as a matter of urgency. The professional perceptions and expectations of final year student nurses should be investigated, so that their initial professional entries could be facilitated, as well as their long term commitment to the professionally active nursing ranks. A longitudinal cohort survey, studying newly qualified nurses, over a period of five or ten years, would render useful information about nurses' professional entry and adaptations, and especially about their job satisfactions and dissatisfactions, as well as factors causing them to abandon the nursing profession or to migrate to other countries.

In order to monitor the nurses who leave the nursing profession on an annual basis, the SANC's annual registration forms should require nurses to indicate whether they are practising full time, part time or not at all. As the annual SANC registrations provide the only country-wide data base about professional nurses in 
the RSA, the possibilities should be investigated that nurses who practise overseas could maintain their SANC registration at reduced fees, to the advantage of these nurses should they return to the RSA, and to the advantage of researchers who could access these records from the SANC's data base. Urgent research would seem to be warranted to find means and ways of making it financially worthwhile for professional nurses to postpone their retirements with 5-10 years. This should include tax concessions, enhanced pension benefits, additional long service bonuses, and the ability to enable them to work when and where they wish to work.

\section{Recommendations for addressing the nursing shortage in South Africa (anticipated to occur between 2005 and 2020)}

Professional nurses aged 65 or older should be allowed to register annually by paying nominal SANC fees only. This might enable retired nurses to continue rendering nursing services in their communities or in old age homes, even if only for one or two shifts per week, after their retirement. This issue needs to be addressed urgently as large numbers of "baby boomers" can be expected to retire between 2005 and 2020, depleting the RSA's numbers of professional nurses, in addition to the unknown numbers who migrate to other countries annually, and in addition to the unknown impact which the HIV/AIDS epidemic might have on the numbers of professional nurses in the RSA between 2005 and 2020.

Retired professional nurses could render valuable health services, even on limited part time basis, in the fields of HIV/AIDS counseling and in termination of pregnancy (TOP) services; these nurses could provide health education presentations at clinics; they could conduct family planning counselling and coordinate home health care services - assuming ever greater significance with the HIV/AIDS epidemic in the RSA. Even the private health care sector could benefit by appointing retired professional nurses to work specific shifts in busy surgical wards when large numbers of patients need to be admitted within a limited period of time. These retired nurses could assist in completing the patients' admission records, enabling the full time professional nurses to attend to the pre- and post- operation care of their patients. Retired professional nurses could render valuable contributions to the health care system of the RSA if and when large numbers of nurses and health care workers might succumb to the HIV/AIDS epidemic, provided that they can work part time during times and in places of their choice, accommodating limitations imposed on their physical activities by their advanced ages.

\section{CONCLUSION}

The largest number of nurses who requested the removal of their names from the SANC's register in 2000 , did so because they reached retirement age. The pool of non-practising nurses who could be recruited to re-enter the profession, appears to be too small to warrant any significant improvement in addressing the anticipated shortage of registered nurses in the RSA between 2005 and 2020. Only 10 (10.9\%) of the respondents were working full time and only four (4.4\%) were working part time in fields other than nursing. However, even these 14 (15.4\%) respondents who were working would not consider reentering the nursing profession because they preferred their current jobs' better salaries, better hours of work, and better job satisfaction than the nursing profession could offer. The only way in which some non-practising nurses could be assisted to re-enter the profession is by offering re-entry courses for those who might contemplate such a re-entry.

The most effective short term solution to this anticipated problem would be to encourage professional nurses to postpone their retirement by $5-10$ years (in order to train larger numbers of student nurses within this period of time). However, further research would be needed to identify which financial and fringe benefits might lure nurses into postponing their retirements. Unless the health care and nursing professions in the RSA can manage to address the anticipated crisis of nurse shortages between 2005 and 2020, the health care services rendered to the people of the RSA might be compromised. Almost two decades ago Searle (1987:288) warned that: "The shortage of professional nurses is the problem that needs the most urgent attention from nurse leaders world wide... it can determine the future of nursing in the next two decades". Fourteen years later other authors echoed the same warning: "The prospect of medical and 
technological efficiency without skilled nurses to provide human care, even on a basic level, has provided a challenge of pandemic proportions. The world's attention is focusing on what can be done to alleviate the shortage of nurses and provide for the future" (Purnell et al. 2001:179). One way of alleviating the shortage of nurses is to encourage retired nurses to continue working even if only for limited shifts per week. Letvak (2002:391) warns that "it is imperative that policies be developed if we are to retian older nurses and assure an adequate supply of our most experienced RNs... The older nurse does not want special treatment, only to be treated fairly... Aging workers are our future - the job you save may be your own".

\section{ACKNOWLEDGEMENTS}

The South African Nursing Council (SANC) is thanked for supplying the name and address stickers of persons who requested to have their names removed from the SANC's registers. Each person who completed and returned a questionnaire is thanked for his/her participation, without which no research report could have materialised.

\section{LIST OF REFERENCES}

BUERHAUS, PI 1998: Is another RN shortage looming? Nursing Outlook. 46(3):103-108.

BURNS, N \& GROVE, SK 2001: The practice fo nursing research: conduct, critique and utilization. Philadelphia: WB Saunders.

CILLIERS, G1984: Occupational study of nurses. Part 3. The work situation of nurses two years after qualifying. Pretoria: Human Sciences Research Council (HSRC).

EHLERS, VJ 1994: A profile of non-practising registered nruses who attended a professional re-entry course in Pretoria and Johannesburg in 1992: their expectations and implications for employing bodies. Curationis. 17(4):20-26.

LETVAK, S 2002: Retaining the older nurse. Journal of Nursing

Administration. 32(7/8):387-392.

MCNEESE-SMITH, DK 2000: Job stages of entry, mastery, and disengagement among nurses. Journal of Nursing Administration. 30(3):140-147.

MILLS, AC \& BLAESING, SL 2000: A lesson from the last nursing shortage. Journal of Nursing Administration. 36(6):309-315. MINNICK, AF 2000: Retirement, the nursing workforce, and the year 2005. Nursing Outlook. 48(5):211-217.

PETERSON, CA 2001: Nursing shortage: not a simple problem - no easy answers. Online Journal of Issues in Nursing. Published January 31, 2001: pp1-9. Accessed at http:// www.nursingworld.org/ojin/topic14/tpc14_1.htm

POLIT, DF \& HUNGLER, BP 1991: Nursing research: principles and methods. $4^{\text {th }}$ edition. Philadelphia: JB Lippincott.

PURNELL, MJ; HORNER, D; GONZALES, J \& WESTMAN, N 2001: The nursing shortage: revisioning the future. Journal of Nursing Administration. 31(4):179-186.

SEARLE, C 1987: Ethos of nursing and midwifery. A general perspective. Durban: Butterworths.

Sochalski, J 2001: Quality of care, nurse staffing, and patient outcomes. Policy, Politics and Nursing Practice. 2(1). (EBSCO

Online- Article: http://www.us.ebsco.com/online/ direct.asp?ArticleID=2U90WR1QVVB4FNVTCODP\&Target=Abstract). SOOTHILL, K; HENRY, C \& KENDRICK, K 1992: Themes and perspectives in nursing. London: Chapman \& Hall.

TANNER, CA \& BELLACK, JP 2001: Editorial: resolving the nursing shortage: replacement plus one. Journal of Nursing Education. 40(3):99-100.

TAYLOR, MA \& COVALESKI, MA 1985: Predicting nurses' turnover and internal transfer behavior. Nursing Research, 34(4):237-241. 